\title{
Life-threatening massive pulmonary embolism rescued by venoarterial- extracorporeal membrane oxygenation
}

Fillipo Corsi ${ }^{1,2}$, Guillaume Lebreton ${ }^{3}$, Nicolas Bréchot ${ }^{2}$, Guillaume Hekimian², Ania Nieszkowska², Jean-Louis Trouillet ${ }^{2}$, Charles-Edouard Luyt ${ }^{2}$, Pascal Leprince ${ }^{3}$, Jean Chastre ${ }^{2}$, Alain Combes ${ }^{2}$ and Matthieu Schmidt ${ }^{2,4^{*}}$

\begin{abstract}
Background: Despite quick implementation of reperfusion therapies, a few patients with high-risk, acute, massive, pulmonary embolism (PE) remain highly hemodynamically unstable. Others have absolute contraindication to receive reperfusion therapies. Venoarterial-extracorporeal membrane oxygenation (VA-ECMO) might lower their right ventricular overload, improve hemodynamic status, and restore tissue oxygenation.

Methods: ECMO-related complications and 90-day mortality were analyzed for 17 highly unstable, ECMO-treated, massive PE patients admitted to a tertiary-care center (2006-2015). Hospital- discharge survivors were assessed for long-term health-related quality of life. A systematic review of this topic was also conducted.

Results: Seventeen high-risk PE patients [median age 51 (range 18-70) years, Simplified Acute Physiology Score II (SAPS II) 78 (45-95)] were placed on VA-ECMO for 4 (1-12) days. Among 15 (82\%) patients with pre-ECMO cardiac arrest, seven (41\%) were cannulated during cardiopulmonary resuscitation, and eight (47\%) underwent pre-ECMO thrombolysis. Pre-ECMO median blood pressure, $\mathrm{pH}$, and blood lactate were, respectively: $42(0-106) \mathrm{mmHg}, 6.99$ (6.54-7.37) and 13 (4-19) mmol/L. Ninety-day survival was 47\%. Fifteen (88\%) patients suffered in-ICU severe hemorrhages with no impact on survival. Like other ECMO-treated patients, ours reported limitations of all physical domains but preserved mental health 19 (4-69) months post-ICU discharge.

Conclusions: $V A-E C M O$ could be a lifesaving rescue therapy for patients with high-risk, acute, massive PE when thrombolytic therapy fails or the patient is too sick to benefit from surgical thrombectomy. Because heparin-induced clot dissolution and spontaneous fibrinolysis allows ECMO weaning within several days, future studies should investigate whether VA-ECMO should be the sole therapy or completed by additional mechanical clot-removal therapies in this setting.
\end{abstract}

Keywords: Extracorporeal membrane oxygenation, Massive pulmonary embolism, Cardiogenic shock, Long-term quality of life

\footnotetext{
* Correspondence: matthieu.schmidt@aphp.fr

${ }^{2}$ Medical Intensive Care Unit, iCAN, Institute of Cardiometabolism and

Nutrition, Hôpital de la Pitié-Salpêtrière, Assistance Publique-Hôpitaux de

Paris, Université Pierre-et-Marie-Curie, Paris 6, 47, bd de l'Hôpital, 75651 Paris

Cedex 13, France

${ }^{4}$ Service de Réanimation Médicale, iCAN, Institute of Cardiometabolism and

Nutrition, Hôpital de la Pitié-Salpêtrière, 47, bd de l'Hôpital, 75651 Paris

Cedex 13, France

Full list of author information is available at the end of the article
} 


\section{Background}

Acute, massive high-risk pulmonary embolism (PE) is defined as an embolus sufficiently obstructing pulmonary blood flow to cause right ventricular (RV) failure, hypoxemia, and hemodynamic instability [1]. Although the epidemiology of massive PE is difficult to determine, it remains a significant cause of cardiovascular morbidity and mortality worldwide, with overall in-hospital mortality rates ranging from $25 \%$ for patients with cardiogenic shock to $65 \%$ for those requiring cardiopulmonary resuscitation $[1,2]$. The latest European guidelines enhance the clinical classification, based on the estimated PE-related early mortality risk, defined by in-hospital or 30-day mortality, with high-risk PE being suspected or confirmed in the presence of shock or persistent arterial hypotension [3]. Treatment is based on bedside hemodynamic and respiratory support, unfractionated heparin infusion (UFH), and reperfusion therapy with systemic thrombolytic agents (class IB), surgical pulmonary embolectomy (class IC) or percutaneous catheter-directed thromboaspiration or embolectomy (class IIaC) [3]. Because of contraindications or major clinical instability, a few patients are not amenable to reperfusion therapies or fail to improve after this treatment. For them, venoarterial-extracorporeal membrane oxygenation (VA-ECMO) is one of the most reliable and quickest ways to decrease RV overload, improve RV function and hemodynamic status, and restore tissue oxygenation. Although ECMO is increasingly available and mobile ECMO teams, if locally available, can assure rapid deployment of this salvage therapy, ECMO data in this context are limited [4-7]. We describe herein our tertiary-care center's experience with VA-ECMOtreated patients with acute, massive, high-risk PE, and report their short- and long-term outcomes.

\section{Methods \\ Patients}

We retrospectively analyzed the ECMO database of our 26-bed intensive care unit (ICU), to identify all the patients referred (June 2006-June 2015) with suspected or confirmed high-risk PE, indicating VA-ECMO support. PE was diagnosed using the diagnostic strategy tools of the latest European Society of Cardiology guidelines [3]. VA-ECMO indications were: acute refractory cardiovascular failure, defined as evidence of tissue hypoxia (e.g., extensive skin mottling or elevated blood lactate) concomitant with adequate intravascular volume status; severely diminished RV or left ventricular ejection fraction (RV/LVEF); low cardiac index $\left(\leq 2.1 \mathrm{~L} / \mathrm{min} / \mathrm{m}^{2}\right)$; sustained hypotension despite high-dose catecholamine infusion (epinephrine $\geq 1 \mathrm{\gamma} / \mathrm{kg} / \mathrm{min}$ or dobutamine $\geq 20 \gamma /$ $\mathrm{kg} / \mathrm{min}+$ norepinephrine $\geq 1 \mathrm{\gamma} / \mathrm{kg} / \mathrm{min}$ ). ECMO exclusion criteria were malignancies with fatal prognosis within
5 years or irreversible neurological pathologies and decisions to limit therapeutic interventions.

VA-ECMO cannulas were surgically inserted by trained cardiovascular surgeons with femoral-femoral $23 \mathrm{~F}$ to $29 \mathrm{~F}-15 \mathrm{~F}$ to $18 \mathrm{~F}$ cannula as previously described [8-10]. An additional $7 \mathrm{~F}$ catheter was systematically inserted into the femoral artery to prevent leg ischemia. For highly unstable patients, our institution's Mobile ECMO Unit traveled to primary-care hospitals with a portable ECMO system, implanted the device at beside in the ICU and transported the patient to our center. When cannulation was done during surgical pulmonary embolectomy, the inflow cannula was placed in the right atrium (RA) and the outflow line in the main pulmonary artery (PA). Pump speed was adjusted to obtain blood flow of $2.5-3.5 \mathrm{~L} / \mathrm{min}$ with intravenous UHF administered to maintain the activated partial thromboplastin time at two to three times control levels (see Additional file 1 for details on ECMO management)..

\section{Pre-ECMO data collection}

At ICU admission, we collected the following information: demographics (age, sex, body mass index), admission disease-severity scores (severity of underlying conditions according to the McCabe and Jackson [11] and Charlson scores [12]); presence of venous-thromboembolic risk factors; Simplified Acute Physiology Score (SAPS) II [13] and Sequential Organ Failure Assessment (SOFA) score [14]). During the pre-ECMO period, the inotrope score, defined as dobutamine dose $(\gamma / \mathrm{kg} / \mathrm{min})+[$ norepinephrine dose $(\gamma / \mathrm{kg} / \mathrm{min})+$ epinephrine dose $(\gamma / \mathrm{kg} / \mathrm{min})] \times 100$ [15]; cardiac arrest with its related "no-flow" and "low-flow" durations; blood gas analyses, and troponin Ic were noted. The following Doppler echocardiography variables were always recorded: RV/LV dimension ratio, LVEF, and visualization of a PA thrombus, before ECMO insertion. Similarly, proximal PE and pulmonary infarction on chest computed tomography $(\mathrm{CT})$ scans were recorded. Lastly, pre-ECMO reperfusion therapies (including thrombolysis, surgical thrombectomy or percutaneous catheter-directed thromboaspiration or embolectomy), ECMO-related complications, and post-ECMO information were collected.

\section{Outcome variables}

The main outcome variables included ECMO weaning, survival to hospital discharge, 90-day survival, and longterm survival (evaluated in September 2015). We also calculated each patient's SOFA scores at cannulation and days 1,3 , and 7 ; the inotrope score 24 hours postcannulation; ECMO and mechanical ventilation durations. Lastly, in-ICU complications, e.g., severe hemorrhage, arterial ischemia, surgical wound infection, stroke, and renal replacement therapy requirement, were recorded. Bleeding complications were reported using the Global Utilization 
of Streptokinase and TPA for Occluded arteries (GUSTO) classification [16, 17]. Briefly, severe life-threatening hemorrhage was intracerebral bleeding or resulted in substantial hemodynamic compromise requiring treatment (GUSTO 1). GUSTO 2 defined moderate bleeding as the need for transfusion, whereas GUSTO 3 referred to other bleeding, not requiring transfusion or causing hemodynamic compromise. Lastly, the number of packs of blood products transfused was also collected.

In September 2015, a telephone interview with survivors evaluated their health-related quality of life (HRQOL), using the French version of the Medical Outcome Study-Short Form 36-item (SF-36) questionnaire. Its 36 items are combined to evaluate eight domains (physical functioning, role-physical, body pain, general health, vitality, social functioning, role-emotional, and mental health) [18]. The aggregate physical (PCS) and mental component summary scores (MCS) were then computed as recommended [18]. Our patients' mean SF36 levels were compared to those obtained for French age- and sex-matched controls with no adverse conditions. Anxiety and depression symptoms were assessed with the Hospital Anxiety and Depression Scale [19], with respective HAD-A and HAD-D subscale scores $\geq 8$ / 21 considered clinically significant [19]. Post-traumatic stress disorder (PTSD)-related symptoms were assessed with the Impact of Event Scale (IES) [20], with total IES scores $\geq 30 / 75$ points indicating a high risk for PTSD. Other long-term outcome variables were: instrumental activities of daily living (IADL) scale score [21], recurrence of thromboembolic events, chronic dyspnea, chronic thromboembolic pulmonary hypertension (CTEPH) diagnosis, persistent anticoagulant use, and return to work. To put our massive PE ECMO-treated patients' questionnaire scores into perspective, we searched the literature for other studies reporting long-term outcomes of ECMOtreated patients, e.g., refractory septic shock [22] or acute respiratory disease syndrome (ARDS) [23].

In accordance with the ethical standards of our hospital's Institutional Review Board and French law, informed consent was not necessary for analyses of demographic, physiological, and hospital-outcome data, because this retrospective observational study did not modify existing diagnostic or therapeutic strategies. The National Commission for Informatics and Liberties (CNIL) approved this study (number 1950673). Survivors gave oral consent to participate in the telephone interview conducted by the same investigator (MS).

\section{Literature review}

We conducted a systematic MEDLINE database literature review through the PubMed search engine with a global search strategy applying pre-specified selection and outcome. We combined the terms "extracorporeal life support" or "extracorporeal membrane oxygenation" with the terms "pulmonary embolism" or "acute pulmonary embolism" or "massive pulmonary embolism". See Additional file 1 for details on methodology and review results.

\section{Statistical analyses}

Results are expressed as numbers (\%) or median (range). Continuous variables were compared with Student's $t$ test or the Mann-Whitney $U$ test, as appropriate, whereas categorical variables were compared with chisquare tests. Analyses were performed using StatView v5.0 software (SAS Institute Inc., Cary, NC, USA) and a two-sided $p<0.05$ defined significance.

\section{Results}

\section{Study population}

During the 10 -year study period, 17 patients [11 females; median age 51 (18-70) years] received ECMO for suspected $(n=2)$ or confirmed $(n=15)$ massive PE (Fig. 1$)$. Median SAPS II and SOFA score were high, respectively, 78 (45-95) and 12 (8-16); 11 (65\%) patients had predisposing factors for venous thromboembolism (Table 1 ). Fifteen $(82 \%)$ patients suffered pre-ECMO cardiac arrest, with seven (41\%) of them cannulated during cardiopulmonary resuscitation. Two other patients received ECMO for refractory cardiogenic shock. Our institution's Mobile ECMO Unit implanted peripheral femoral-femoral VA-ECMO into seven (41\%) patients; nine (53\%) were cannulated at beside in our department. Two patients received ECMO for hemodynamic status deterioration during surgical thrombectomy for acute pulmonary embolism, including one with a RA-PA central configuration. All patients required hemodynamic support with vasoactive drugs, resulting in a median inotrope score of $100(1.8-760) \mu \mathrm{g} / \mathrm{kg} / \mathrm{min}$ at ECMO cannulation. Pre-ECMO median blood pressure, $\mathrm{pH}$ and blood lactate were, respectively: $42(0-106) \mathrm{mmHg}, 6.99$ (6.54-7.37) and $13(4-19) \mathrm{mmol} / \mathrm{L}$. Transthoracic or transesophageal echocardiography visualized major RV dilation in all patients (RV/LV dimensions ratio 1.3 [0.7-1.6]), with a proximal PA thrombus in three. Chest CT scan confirmed PE in 12 patients of whom ten had proximal PE. Eight patients received unsuccessful systemic fibrinolytic therapy pre-ECMO according to standard protocols [24]. Peripheral VA-ECMO was implanted for refractory cardiogenic shock several hours post-surgical embolectomy for one patient, whereas another was cannulated during the procedure in the operating room (RA-PA central configuration). Two patients underwent catheter-directed thromboaspiration: one on ECMO and the other failed pre-ECMO because of hemodynamic instability. As described in Tables 1 and 2, 24 hours on ECMO rapidly corrected $\mathrm{pH}(6.99$ [6.54-7.37] vs. 7.42 


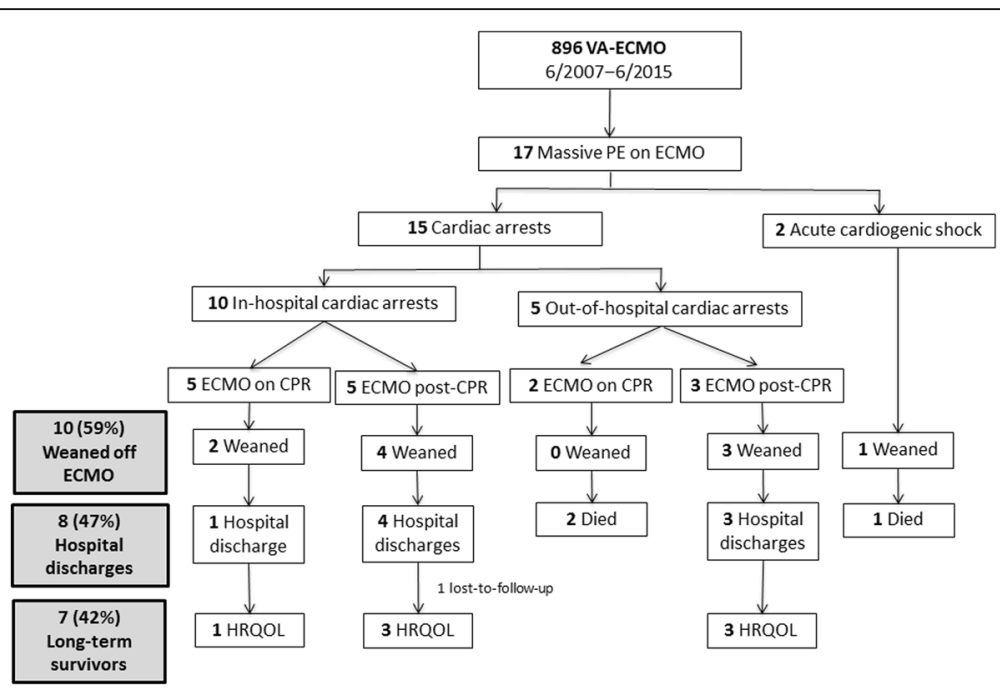

Fig. 1 Study flow chart. CPR cardiopulmonary resuscitation, HRQOL health- related quality of life, PE pulmonary embolism, VA-ECMO venoarterialextracorporeal membrane oxygenation

[7.19-7.69]) and serum lactate (13.3 [4.2-19.0] vs. 3.2 [1.1-12.3] $\mathrm{mmol} / \mathrm{L})$. In addition, one patient's follow-up CT scans showed major clot dissolution with residual thrombi 15 days later, including 8 days on ECMO and prolonged heparin treatment but without systemic fibrinolytic therapy (see Additional file 2).

\section{0-Day survival and hospital discharge}

Table 2 reports ECMO-related complications and shortterm outcomes according to 90-day status. Almost all patients experienced at least one major ECMO-related complication; 15 (88\%) had a moderate-to-severe hemorrhage classified as GUSTO $\leq 2$ with a median of 4 $(0-29)$ packed red-cell and $5(0-11)$ fresh-frozen plasma units transfused. Eight out of 15 patients (47\%) had a SOFA $_{\text {liver }} \geq 1$ before ECMO cannulation, which was not associated with a higher rate of severe bleeding $(p=0.94)$.

Thirteen $(76 \%)$ patients received renal replacement therapy during their ICU stay. Both complications had no impact on 90-day survival. Other complications included: ischemic stroke in four patients, with two recovering normal neurological function at hospital discharge; arterial ischemia in two patients, one each underwent lower limb or toe amputation, and two surgical cannularelated, wound-infection debridement.

Nine patients died within 90 days post-ICU admission: seven on ECMO (six of cardiac arrest-related multiorgan failure and one of refractory cardiogenic shock despite ECMO support), and one each after successful ECMO weaning of secondary cardiogenic shock with multiorgan failure or PE recurrence with sudden death 6 days postECMO removal despite adequate anticoagulation. One patient, still hospitalized 90 days post-ICU admission, was discharged after 135 days in the hospital. It is worth noting that only one out of the seven patients cannulated while undergoing cardiopulmonary resuscitation (CPR) was discharged alive from hospital (Fig. 1). The eight (47\%) hospital survivors, including the patient with central ECMO, were discharged after 4 (3-11) days on ECMO, 17 (7-91) in-ICU days and 45 (22-135) inhospital days. Compared with patients who died within 90 days, it is worth noting that 90-day survivors had significantly lower inotrope scores 24 hours postcannulation (Fig. 2), and lower SAPS II and SOFA scores on ECMO days 1 and 3.

\section{Long-term outcomes}

IADL, SF-36, HAD, and IES questionnaires were administered to seven of the eight long-term survivors after median follow-up of 19 (4-74) months post-hospital discharge. One patient, known to be alive at home 1 month before follow-up, could not be reached. Daily-living activities were normal for five patients, whereas two others reported moderate limitations due to physical impairment after lower limb or toe amputation: IADL scores of 24 and 20, respectively. Comparison with age- and sexmatched controls highlighted limitations of all physical domains but preserved mental health function. However, PCS and MCS were similar to those of other ECMOassisted refractory septic shock and ECMO-treated refractory ARDS patients (Fig. 3). Our respondents exhibited significant anxiety (28\%) or depression symptoms $(43 \%)$, or were at risk for PTSD (28\%), with only two (28\%) returning to their previous work. Eighty-six percent of long-term survivors were still taking 
Table 1 Clinical characteristics of the 17 patients at the time of VA-ECMO implantation

\begin{tabular}{|c|c|}
\hline Variable & Value \\
\hline Age, yr, median (range) & $51(18-70)$ \\
\hline Male & $6(35)$ \\
\hline Body mass index, $\mathrm{kg} / \mathrm{m}^{2}$ & $29(20-35)$ \\
\hline McCabe and Jackson score $\geq 2$ & $3(18)$ \\
\hline Charlson score $\geq 2$ & $5(29)$ \\
\hline SAPS $\|$ & $78(45-95)$ \\
\hline SOFA score & $12(8-16)$ \\
\hline Predisposing factors for venous thromboembolism & $11(65)$ \\
\hline Postoperative status & 4 \\
\hline Immobility due to sitting & 2 \\
\hline Oral contraception & 1 \\
\hline Previous venous thromboembolism & 3 \\
\hline Postpartum period & 3 \\
\hline $\begin{array}{l}\text { Hospitalization for HF or AF (within } \\
\text { previous } 3 \text { months) }\end{array}$ & 2 \\
\hline ECMO implantation by Mobile ECMO Unit & $7(41)$ \\
\hline Femoral-femoral VA-ECMO & $16(94)$ \\
\hline Pre-ECMO cardiac arrest & $15(88)$ \\
\hline No-flow time, $\min$ & $0(0-11)$ \\
\hline Low-flow time, min & $30(10-85)$ \\
\hline ECMO during cardiopulmonary resuscitation & $7(41)$ \\
\hline Pre-ECMO systolic blood pressure, $\mathrm{mmHg}$ & $55(0-130)$ \\
\hline Pre-ECMO mean blood pressure, $\mathrm{mmHg}$ & $42(0-106)$ \\
\hline Pre-ECMO heart rate, bpm & $95(0-177)$ \\
\hline Pre-ECMO inotrope score, $\mu \mathrm{g} / \mathrm{kg} / \mathrm{min}$ & $100(1.8-760)$ \\
\hline $\mathrm{pH}$ & $6.99(6.54-7.37)$ \\
\hline Blood lactate, $\mathrm{mmol} / \mathrm{L}$ & $13.3(4.2-19.0)$ \\
\hline Bicarbonate, mmol/L & $12(3-25)$ \\
\hline Troponin I, $\mu \mathrm{g} / \mathrm{mL}$ & $2.2(0.1-23.7)$ \\
\hline $\mathrm{PaO}_{2} / \mathrm{FiO}_{2}$ ratio & $198(32-674)$ \\
\hline $\mathrm{PaCO}_{2}, \mathrm{mmHg}$ & $48(17-102)$ \\
\hline Bilirubin, $\mathrm{mmol} / \mathrm{L}$ & $8(6-124)$ \\
\hline Prothrombin activity, \% & $34(10-72)$ \\
\hline Pre-ECMO cardiac echocardiography & $17(100)$ \\
\hline RV dilation & $17(100)$ \\
\hline Pulmonary artery thrombus & $3(18)$ \\
\hline LVEF, \% & $40(5-60)$ \\
\hline Pre-ECMO chest $C T$ scan & $12(71)$ \\
\hline Proximal PE & $10(59)$ \\
\hline Pulmonary infarction & $3(18)$ \\
\hline RV/LV dimensions ratio & $1.3(0.7-1.6)$ \\
\hline Pre-ECMO systemic fibrinolytic therapy & $8(47)$ \\
\hline Pre-ECMO surgical thrombectomy & $2(12)$ \\
\hline Pre-ECMO catheter-directed thromboaspiration & $1(6)$ \\
\hline
\end{tabular}

Categorical variables are expressed as $n$ (\%) and continuous variables as median (range), unless stated otherwise

VA-ECMO venoarterial-extracorporeal membrane oxygenation, SAPS // Simplified Acute Physiology Score II, SOFA Sequential Organ Failure Assessment, AF atrial fibrillation, $H F$ heart failure, $R V$ right ventricular, $L V E F$ left ventricular ejection fraction anticoagulants; none reported chronic dyspnea, PE recurrence or CTEPH diagnosis during their medical follow-up.

\section{Discussion}

To our knowledge, this is the largest follow-up study on VA-ECMO-treated life-threatening PE in the modern era. Despite extreme disease severity at ECMO implantation, multiorgan failure and 91\% SAPS II-predicted mortality, $47 \%$ of these patients were alive at 90 days with acceptable long-term HRQOL. Nevertheless, after median 19-month follow-up, physical limitations were frequently reported, with normal mental health function. In addition, anxiety, depression or PTSD symptoms persisted for almost one-third of the survivors.

To date, literature on VA-ECMO, as rescue treatment for extremely severe, massive $\mathrm{PE}$, had been limited to small case series or case reports with no long-term outcome evaluation see Additional file 3 (Table 3). In 2007, Maggio et al. reported on 21 cohort patients diagnosed with high-risk PE between 1992 and 2005 [4]: 19 were cannulated with VA bypass, six received pre-ECMO thrombolytic therapy and eight were cannulated after suction or surgical pulmonary embolectomy failed. Overall survival was $62 \%$, with catastrophic neurological events responsible for $50 \%$ of the deaths. In our study, severe bleeding episodes occurred in 15 (88\%) patients requiring packed red-cell and/or fresh-frozen plasma transfusions. Major bleeding, including intracranial hemorrhage is a well-recognized ECMO complication [25], with numerous identified risk factors, e.g., thrombocytopenia, vasopressor requirement, and cardiopulmonary resuscitation $[25,26]$. Due to previous thrombolytic treatment and curative anticoagulation, life-threatening PE on ECMO may carry additional risk factors of major bleeding during this circulatory support.

Our results highlight that ECMO can provide lifesaving hemodynamic support at bedside for critically ill patients too unstable to tolerate other interventions or refractory to other therapies. A recent survival-prediction model indicated a lower predicted chance of survival for each associated extracardiac organ failure at ECMO onset, which starkly illustrates the crucial impact of VA-ECMO timing for refractory cardiogenic shock [27]. To shorten this interval, mobile ECMO teams able to implant a portable and quick-to-prime ECMO circuit just after the emergency call [28] might help clinicians overcome these difficulties.

Current guidelines for high-risk PE advocate using reperfusion therapy with systemic thrombolytic agents or surgical pulmonary embolectomy [3]. However, those recommendations might be questionable for the sickest patients in severe shock or cardiac arrest, when thrombolysis takes time to be effective and surgery is not 
Table 2 ICU events and outcomes of ECMO-treated massive PE patients according to 90-day survival status

\begin{tabular}{|c|c|c|c|c|}
\hline Event/outcome & All patients $(n=17)$ & Non-survivors $(n=9)$ & Survivors $(n=8)$ & $p$ \\
\hline SAPS II at ICU admission & $78(45-95)$ & $83(71-95)$ & $58(45-91)$ & 0.04 \\
\hline Shock onset-to-ECMO interval, $\mathrm{h}$ & $3(1-24)$ & $3(1-24)$ & $3.5(1-12)$ & 0.92 \\
\hline Extracorporeal blood flow during the $1 \mathrm{st} 24 \mathrm{~h}, \mathrm{~L} / \mathrm{min}$ & $3.3(3.0-4.2)$ & $3.3(3.2-4.2)$ & $3.2(3.0-3.9)$ & 0.19 \\
\hline SOFA score at ECMO cannulation & $12(8-19)$ & $15(11-19)$ & $12(8-15)$ & 0.11 \\
\hline Inotrope score at ECMO cannulation, $\mu \mathrm{g} / \mathrm{kg} / \mathrm{min}$ & $100(2-760)$ & $75(2-730)$ & $143(92-760)$ & 0.17 \\
\hline Inotrope score after $24 \mathrm{~h}$ of ECMO, $\mu \mathrm{g} / \mathrm{kg} / \mathrm{min}$ & $50(0-660)$ & $75(41-660)$ & $6(0-51)$ & 0.001 \\
\hline pH ECMO-day 1 & $7.42(7.19-7.69)$ & $7.40(7.19-7.57)^{a}$ & $7.44(7.32-7.69)$ & 0.79 \\
\hline Blood lactate ECMO-day $1, \mathrm{mmol} / \mathrm{L}$ & $3.2(1.1-12.3)$ & $4.5(1.1-12.3)^{\mathrm{a}}$ & $2.3(1.1-3.5)$ & 0.17 \\
\hline \multicolumn{5}{|l|}{ SOFA score } \\
\hline ECMO-day 1 & $14(11-18)$ & $14(13-18)$ & $12(11-16)$ & 0.04 \\
\hline ECMO-day 3 & $13(8-18)$ & $15(12-18)$ & $13(8-15)$ & 0.03 \\
\hline ECMO-day 7 & $6(1-19)$ & $10(7-13)$ & $6(1-19)$ & 0.29 \\
\hline \multicolumn{5}{|l|}{ In-ICU complications } \\
\hline Hemorrhage $\leq$ GUSTO 2 & $15(88)$ & $8(89)$ & $7(88)$ & 0.92 \\
\hline RRT & $13(76)$ & $6(67)$ & $7(88)$ & 0.31 \\
\hline Stroke & $4(24)$ & $1(11)$ & $3(38)$ & 0.2 \\
\hline Surgical wound infection & $2(12)$ & 0 & $2(25)$ & - \\
\hline Arterial ischemia & $1(6)$ & 0 & $1(12)$ & - \\
\hline Packed red-cell units transfused & $4(0-29)$ & $4(0-6)$ & $9(0-29)$ & 0.7 \\
\hline Fresh-frozen plasma units transfused & $5(0-11)$ & $3(0-8)$ & $8(0-11)$ & 0.7 \\
\hline Tracheotomy & $2(12)$ & 0 & $2(25)$ & - \\
\hline ECMO duration, days & $4(1-12)$ & $3(1-13)$ & $4(3-11)$ & 0.28 \\
\hline MV duration, days & $10(1-43)$ & $3(1-24)$ & $13(1-43)$ & 0.03 \\
\hline ICU LOS, days & $10(1-91)$ & $3(1-24)$ & $17(7-91)$ & 0.009 \\
\hline Hospital LOS, days & $22(1-135)$ & $6(1-36)$ & $45(22-135)$ & 0.004 \\
\hline
\end{tabular}

Categorical variables are expressed as $\mathrm{n}(\%)$ and continuous variables as median (range)

ICU intensive care unit, ECMO extracorporeal membrane oxygenation, PE pulmonary embolism, SAPS II Simplified Acute Physiology Score II, SOFA Sequential Organ Failure Assessment, GUSTO Global Utilization of Streptokinase and TPA for Occluded arteries, RRT renal replacement therapy, MV mechanical ventilation, LOS length of stay

${ }^{\text {a }}$ Three patients died within less than $24 \mathrm{~h}$ on ECMO

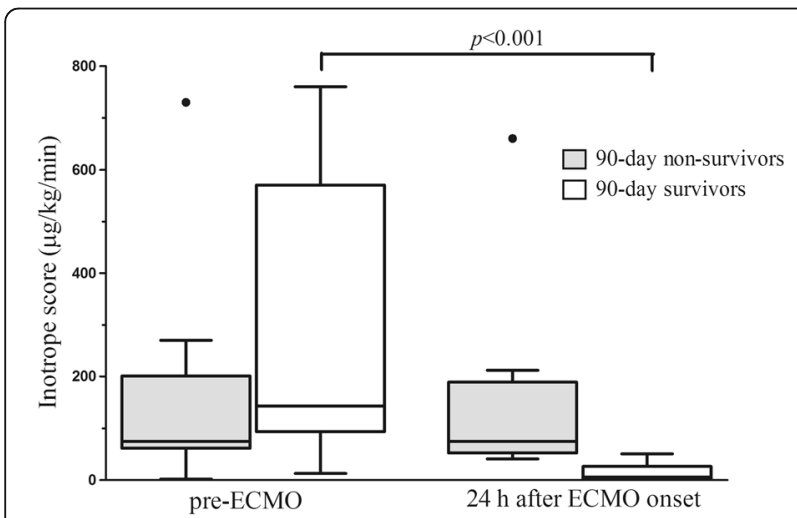

Fig. 2 Box plots of the inotrope score change between pre- and post-VA-ECMO cannulation according to patients' 90-day status. Bold horizontal lines are medians; lower and upper box limits are 25th-75th percentiles; T-bars represent 10th-90th percentiles. ECMO extracorporeal membrane oxygenation immediately available. Therefore, VA-ECMO could be used to rescue patients when thrombolytic treatments fail or as temporary hemodynamic support prior to surgical [29] or catheter-based embolectomy [30]. However, surgical embolectomy is a major intervention requiring sternotomy and cardiopulmonary bypass that carries significant morbidity and mortality in this context of advanced shock and multiorgan failure; hence, VA-ECMO might also be used alone until heparin-induced and spontaneous endogenous thrombolysis permit weaningoff support [5]. Herein, sufficient clot dissolution allowing ECMO removal was obtained within 4 (3-11) days for the eight patients rescued by VA-ECMO alone.

The other rationale supporting surgical thrombectomy on ECMO is to limit the CTEPH risk [29], which has been reported to be $0.1-9.1 \%$ for patients within the first 2 years after symptomatic PE [31]. However, data confirming that hypothesis are lacking. Notably, none of our 


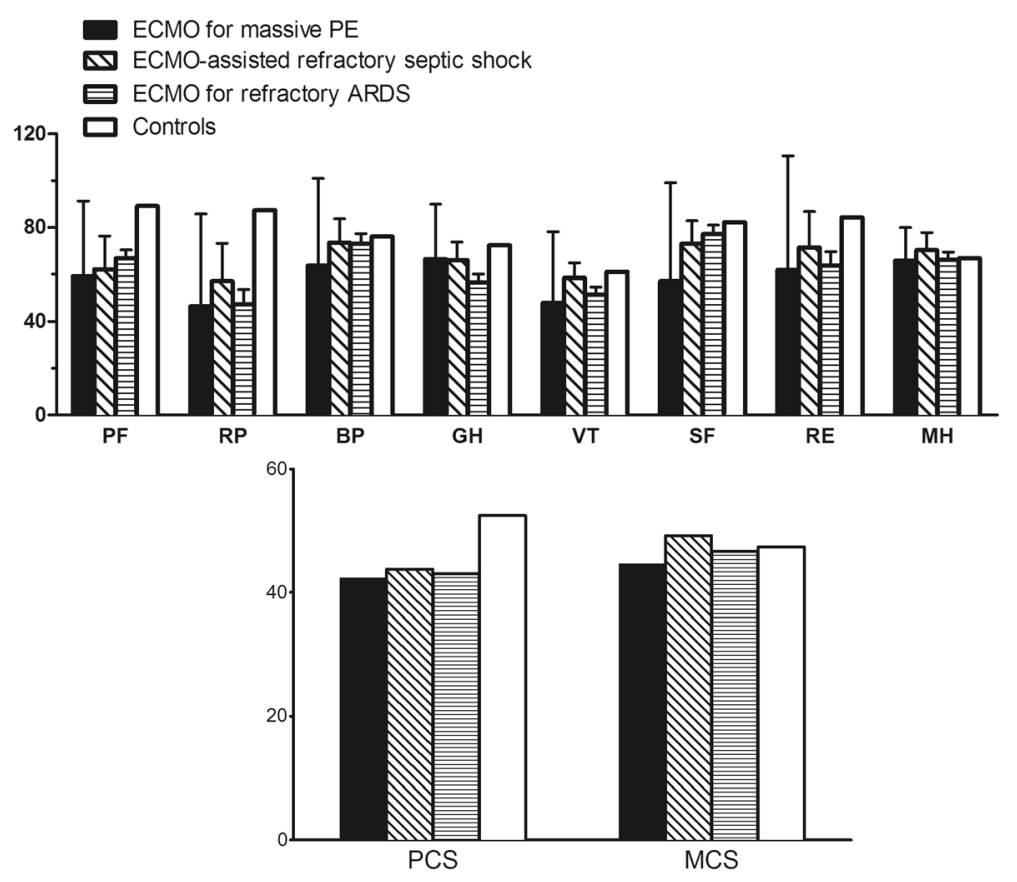

Fig. 3 Comparison of median Short Form-36 scores of our high-risk massive PE survivors treated with VA-ECMO after median 19-month follow-up post-hospital discharge and their age- and sex-matched control subjects [18], 67 venovenous-ECMO-treated acute respiratory distress syndrome (ARDS) survivors at 17-month follow-up [23] and ten VA-ECMO-treated septic shock patients [23]. Higher scores denote better health-related quality of life. ECMO extracorporeal membrane oxygenation, ARDS acute respiratory disease syndrome, PF physical functioning, RP role-physical, BP body pain, GH general health, VT vitality, SF social functioning, RE role-emotional, MH mental health, PCS physical component score, MCS mental component score

long-term survivors developed CTEPH. In addition, despite significant mechanical PA obstruction by massive $\mathrm{PE}$, thrombectomy to prevent CTEPH is not yet systematically advocated [3]. The lack of linear correspondence between the degree of mechanical obstruction and CTEPH risk, because of concomitant small-vessel pulmonary arteriopathy [32], makes the benefit of adding surgical thrombectomy in this context questionable. Lastly, a recent systematic review of case reports and case series published over the past 20 years found similar outcomes for patients who underwent surgical or catheter embolectomy or no additional therapies on ECMO [7]. The benefit of mechanical removal therapies, e.g., catheter or surgical thrombectomy, over exclusive VA-ECMO use warrants further investigation.

Despite very severe disease at ECMO initiation, the 47\% 90-day survival observed for our series is comparable with results reported in studies included in our systematic review (Table 3) and with the $42 \%$ hospital-survival rate of a large international cohort of ECMO-treated refractory cardiogenic shock patients [27]. Despite high numbers of our patients with pre-ECMO cardiac arrest or cannulated during cardiopulmonary resuscitation, our survivors' survival rate was also higher than those reported for ECMOtreated in- and out-of-hospital cardiac arrest $(28.8 \%$ and $4 \%$, respectively) [33, 34]. However, HRQOL evaluated after median 19-month follow-up, was still impaired, compared to sex- and age-matched controls, especially concerning SF-36 physical health and social-functioning domains, while general and mental health were considered satisfactory. Although, case-mix differences make comparisons between series difficult, we observed than our extremely ill patients' SF-36 scores were similar to those of both ECMO-assisted refractory shock [22] and ECMOtreated refractory ARDS patients [23]. Nevertheless, the burden of ECMO-induced physical limitations for our ECMO-treated survivors was still perceptible 19 months post-hospital discharge with back-to-work impact. Although thoroughly described in previous case series [8-10], ECMO-related long-term physical sequelae have not been investigated. Future studies are warranted to prevent these complications and improve their long-term management.

Our study's strengths are the larger number of consecutive patients included and their detailed characterization, and its longitudinal design with median survivor followup 19 months post-ICU discharge. However, our study also has limitations. First, it is a retrospective, singlecenter study. Second, the self-assessed persistently impaired physical health and vitality might not be specific to PE but may represent sequelae of any severe disease requiring prolonged ICU stay and ECMO, including critical 
Table 3 Studies on patients with acute, massive, high-risk PE on VA-ECMO support included in the systematic review

\begin{tabular}{|c|c|c|c|c|c|c|c|c|}
\hline \multirow[t]{2}{*}{ Reference } & \multirow{2}{*}{$\begin{array}{l}\text { Inclusion } \\
\text { dates }\end{array}$} & \multirow{2}{*}{$\begin{array}{l}\text { Patients, } \\
n\end{array}$} & \multicolumn{2}{|l|}{ Pre-ECMO } & \multirow{2}{*}{$\begin{array}{l}\text { Fibrinolytic } \\
\text { therapy (\%) }\end{array}$} & \multirow{2}{*}{$\begin{array}{l}\text { Mechanical PE removal } \\
\text { on ECMO ( } n \text { patients) }\end{array}$} & \multirow{2}{*}{$\begin{array}{l}\text { VA-ECMO-related } \\
\text { complications } \\
\text { ( } n \text { patients) }\end{array}$} & \multirow{2}{*}{$\begin{array}{l}\text { Survival } \\
(\%)\end{array}$} \\
\hline & & & $\begin{array}{l}\text { Cardiac } \\
\text { arrest (\%) }\end{array}$ & $\begin{array}{l}\text { Mechanical PE } \\
\text { removal ( } n \text { patients) }\end{array}$ & & & & \\
\hline $\begin{array}{l}\text { Kawahito } \\
\text { et al. [35] }\end{array}$ & 1994-1998 & 7 & 71 & 0 & 100 & $\begin{array}{l}3 \text { surgical pulmonary } \\
\text { embolectomies }\end{array}$ & 0 & 57 \\
\hline $\begin{array}{l}\text { Maggio } \\
\text { et al. [4] }\end{array}$ & 1992-2005 & $21^{\mathrm{a}}$ & 38 & $\begin{array}{l}6 \text { suction and } 2 \\
\text { surgical pulmonary } \\
\text { embolectomies }\end{array}$ & 29 & $\begin{array}{l}1 \text { suction and } 2 \\
\text { surgical pulmonary } \\
\text { embolectomies }\end{array}$ & $\begin{array}{l}4 \text { catastrophic neurological } \\
\text { events; } 1 \text { dislodged } \\
\text { arterial cannula }\end{array}$ & 62 \\
\hline $\begin{array}{l}\text { Sakuma } \\
\text { et al. [36] }\end{array}$ & 1983-2006 & 7 & NR & 0 & 86 & $\begin{array}{l}1 \text { suction and } 1 \\
\text { surgical pulmonary } \\
\text { embolectomies }\end{array}$ & NR & 57 \\
\hline $\begin{array}{l}\text { Malekan } \\
\text { et al. [5] }\end{array}$ & $2005-2011$ & 4 & $N R$ & 0 & 0 & $\begin{array}{l}1 \text { suction pulmonary } \\
\text { embolectomy }\end{array}$ & None & 100 \\
\hline $\begin{array}{l}\text { Munakata } \\
\text { et al. [30] }\end{array}$ & 1992-2008 & 10 & 90 & $\begin{array}{l}2 \text { suction pulmonary } \\
\text { embolectomies }\end{array}$ & 100 & $\begin{array}{l}7 \text { suction pulmonary } \\
\text { embolectomies }\end{array}$ & 2 major bleeding & 70 \\
\hline Omar et al. [37] & $2007-2011$ & 4 & 50 & $\begin{array}{l}1 \text { suction and } 2 \\
\text { surgical pulmonary } \\
\text { embolectomies }\end{array}$ & 25 & None & $N R$ & 25 \\
\hline Maj et al. [38] & NR & 6 & 100 & None & 66 & $\begin{array}{l}1 \text { surgical pulmonary } \\
\text { embolectomy }\end{array}$ & 3 major bleeding & 33 \\
\hline Swol et al. [39] & 2008-2014 & 5 & 100 & None & 60 & $\begin{array}{l}1 \text { surgical pulmonary } \\
\text { embolectomy }\end{array}$ & 1 major bleeding & 40 \\
\hline Cho et al. [40] & 2000-2013 & 13 & $N R$ & None & 15 & $\begin{array}{l}11 \text { surgical pulmonary } \\
\text { embolectomies }\end{array}$ & $N R$ & $N R$ \\
\hline This study & 2006-2015 & 17 & 88 & $\begin{array}{l}1 \text { suction and } 1 \\
\text { surgical pulmonary } \\
\text { embolectomies }\end{array}$ & 47 & $\begin{array}{l}1 \text { suction and } 1 \\
\text { surgical pulmonary } \\
\text { embolectomies }\end{array}$ & 15 major bleeding & $47^{b}$ \\
\hline
\end{tabular}

$P E$ pulmonary embolism, VA-ECMO venoarterial-extracorporeal membrane oxygenation, NR not reported

${ }^{a}$ Nineteen of the 21 patients were cannulated for VA-ECMO and two were placed on venovenous-ECMO

${ }^{\mathrm{b}}$ Reported at 90 days

illness, muscle wasting, and weakness. Third, we did not perform protocolized follow-up based on long-term cardiac echocardiography and imaging to detect CTEPH development. Further studies focusing on this point are needed to support long-term safety of an ECMO strategy without additional mechanical clot-removal therapies. Lastly, PE diagnosis was confirmed in 15 out of the 17 patients. The remaining two patients had high massive PE suspicion but died within 24 hours after ICU admission without chest $\mathrm{CT}$ scan performed. The family refused autopsy. However, they both had prolonged cardiac arrest with massive RV dilatation on cardiac echocardiography, predisposing factors for venous thromboembolism, and no evidence of right myocardial infarction.

\section{Conclusions}

In conclusion, long-term survival of our 17 VA-ECMOtreated patients with life-threatening, massive $\mathrm{PE}$ reached $47 \%$. Although only limited data support VAECMO effectiveness in this context at present, our results suggest that it could be a lifesaving rescue therapy to rapidly restore hemodynamic status when thrombolytic therapy fails or when the patient is deemed too sick to benefit from medical or surgical treatments. Considering that heparin-induced clot dissolution and spontaneous fibrinolysis allows ECMO weaning after only a few days on support, the benefit of additional mechanical clot-removal therapies, e.g., catheter-based or surgical thrombectomy on ECMO, also warrant investigation.

\section{Additional files}

\section{Additional file 1: Supplementary methods (DOCX $18 \mathrm{~kb}$ )}

Additional file 2: (A) Computed tomography (CT) scan showing a saddle embolus extending into the left and right pulmonary arteries. (B) The same patient's follow-up CT scan obtained 9 days later on VA-ECMO. (C) CT scan obtained 15 days after ICU admission with successful ECMO weaning after 10 days on circulatory support. (DOCX $462 \mathrm{~kb}$ )

Additional file 3: Flow diagram illustrating the identification, selection, and exclusion of articles used in the review. (DOCX $95 \mathrm{~kb}$ )

\section{Abbreviations}

ARDS: Acute respiratory disease syndrome; CT: Computed tomography; CTEPH: Chronic thromboembolic pulmonary hypertension; GUSTO: Global Utilization of Streptokinase and TPA for Occluded arteries; HAD-A and HAD-D: Hospital Anxiety and Depression Scale; HRQOL: Health-related quality of life; IADL: Instrumental activities of daily living; ICU: Intensive care unit; IES: Impact of Event Scale; LVEF: Left ventricular ejection fraction; MCS: Mental component summary scores; PA: Pulmonary artery; 
PCS: Physical component summary scores; PE: Pulmonary embolism; PTSD: Post-traumatic stress disorder; RA: Right atrium; RV: Right ventricular; SAPS II: Simplified Acute Physiology Score II; SF-36: Short Form 36-item Questionnaire; SOFA: Sequential Organ Failure Assessment; UFH: Unfractionated-heparin infusion; VA-ECMO: Venoarterial-extracorporeal membrane oxygenation

\section{Acknowledgements}

None.

\section{Funding}

No funding.

\section{Availability of data and materials Not applicable.}

\section{Authors' contributions}

FC conceived of the study, participated in its design, data collection, coordination, performed the statistical analysis, and drafted the manuscript. $G L$ conceived of the study, participated in its design, and revised the manuscript. NB participated in study design, data collection, and revised the manuscript. GH participated in study design, data collection, and revised the manuscript. AN participated in study design, and revised the manuscript. JLT participated in study design, and revised the manuscript. CEL participated in study design, and revised the manuscript. PL participated in study design, and revised the manuscript. JC participated in study design, and revised the manuscript. AC conceived of the study, participated in its design, and helped to draft the manuscript. MS conceived of the study, participated in its design, data collection, coordination, performed the statistical analysis and drafted the manuscript. All authors read and approved the final manuscript.

\section{Authors' information}

FC is an Italian fellow in the Medical ICU of La Pitié Salpetrière Hospital, Paris, France; GL is an assistant professor in the Cardiac Surgery Department of $\mathrm{La}$ Pitié Salpetrière Hospital Paris, France; NB, GH, AN, and JLT are consultants in the Medical ICU of La Pitié Salpetrière Hospital Paris, France; CEL and JC are professors in the Medical ICU of La Pitié Salpetrière Hospital Paris, France; PL is a professor and the head of the Cardiac Surgery Department of La Pitié Salpetrière Hospital Paris, France; AC is a professor and the head of the Medical ICU of La Pitié Salpetrière Hospital Paris, France; MS is an assistant professor in the Medical ICU of La Pitié Salpetrière Hospital Paris, France.

\section{Competing interests}

Dr. Combes is the primary investigator of the randomized EOLIA trial (NCT01470703) on W-ECMO partially supported by Maquet. Drs. Combes, Schmidt and Bréchot have received honoraria for lectures from Maquet. The other authors declare that they have no competing interests.

\section{Consent for publication}

Not applicable.

\section{Ethics approval and consent to participate}

In accordance with the ethical standards of our hospital's Institutional Review Board and French law, informed consent was not necessary for analyses of demographic, physiological and hospital-outcome data, because this retrospective observational study did not modify existing diagnostic or therapeutic strategies. The National Commission for Informatics and Liberties (CNIL) approved this study (number 1950673).

\section{Author details}

${ }^{1}$ Dipartimento di Anestesia e Rianimazione, Policlinico Universitario A Gemelli, Università Cattolica Del Sacro Cuore, Rome, Italy. ${ }^{2}$ Medical Intensive Care Unit, iCAN, Institute of Cardiometabolism and Nutrition, Hôpital de la Pitié-Salpêtrière, Assistance Publique-Hôpitaux de Paris, Université Pierre-et-Marie-Curie, Paris 6, 47, bd de l'Hôpital, 75651 Paris Cedex 13, France. ${ }^{3}$ Cardiac Surgery Department, iCAN, Institute of Cardiometabolism and Nutrition, Hôpital de la Pitié-Salpêtrière, Assistance Publique-Hôpitaux de Paris, Université Pierre-et-Marie-Curie, Paris 6, 47, bd de I'Hôpital, 75651 Paris Cedex 13, France. ${ }^{4}$ Service de Réanimation Médicale, iCAN, Institute of Cardiometabolism and Nutrition, Hôpital de la Pitié-Salpêtrière, 47, bd de l'Hôpital, 75651 Paris Cedex 13, France.
Received: 15 November 2016 Accepted: 28 February 2017

Published online: 28 March 2017

\section{References}

1. Agnelli G, Becattini C. Acute pulmonary embolism. N Engl J Med. 2010; 363(3):266-74

2. Kasper W, Konstantinides S, Geibel A, Olschewski M, Heinrich F, Grosser KD, Rauber K, Iversen S, Redecker M, Kienast J. Management strategies and determinants of outcome in acute major pulmonary embolism: results of a multicenter registry. J Am Coll Cardiol. 1997;30(5):1165-71.

3. Konstantinides SV, Torbicki A, Agnelli G, Danchin N, Fitzmaurice D, Galie N, Gibbs JS, Huisman MV, Humbert M, Kucher N, et al. ESC guidelines on the diagnosis and management of acute pulmonary embolism. Eur Heart J. 2014;35(43):3033-69. 3069a-3069k.

4. Maggio P, Hemmila M, Haft J, Bartlett R. Extracorporeal life support for massive pulmonary embolism. J Trauma. 2007;62(3):570-6.

5. Malekan R, Saunders PC, Yu CJ, Brown KA, Gass AL, Spielvogel D, Lansman SL. Peripheral extracorporeal membrane oxygenation: comprehensive therapy for high-risk massive pulmonary embolism. Ann Thorac Surg. 2012;94(1):104-8.

6. Pavlovic G, Banfi C, Tassaux D, Peter RE, Licker MJ, Bendjelid K, Giraud R Peri-operative massive pulmonary embolism management: is veno-arterial ECMO a therapeutic option? Acta Anaesthesiol Scand. 2014;58(10):1280-6.

7. Yusuff HO, Zochios V, Vuylsteke A. Extracorporeal membrane oxygenation in acute massive pulmonary embolism: a systematic review. Perfusion. 2015; 30(8):611-6.

8. Aissaoui N, Luyt CE, Leprince P, Trouillet JL, Leger P, Pavie A, Diebold B, Chastre J, Combes A. Predictors of successful extracorporeal membrane oxygenation (ECMO) weaning after assistance for refractory cardiogenic shock. Intensive Care Med. 2011;37(11):1738-45.

9. Combes A, Leprince P, Luyt CE, Bonnet N, Trouillet JL, Leger P, Pavie A, Chastre J. Outcomes and long-term quality-of-life of patients supported by extracorporeal membrane oxygenation for refractory cardiogenic shock. Crit Care Med. 2008:36(5):1404-11.

10. Mirabel M, Luyt CE, Leprince P, Trouillet JL, Leger P, Pavie A, Chastre J, Combes A. Outcomes, long-term quality of life, and psychologic assessment of fulminant myocarditis patients rescued by mechanical circulatory support. Crit Care Med. 2011:39(5):1029-35.

11. Jackson GG, Arana-Sialer JA, Andersen Br Grieble HG, McCabe WR. Profiles of pyelonephritis. Arch Intern Med. 1962;110:63-75.

12. Charlson ME, Pompei $P$, Ales $K L$, Mackenzie CR. A new method of classifying prognostic comorbidity in longitudinal studies: development and validation. Chronic Dis. 1987:40(5):373-83.

13. Le Gall JR, Lemeshow S, Saulnier F. A new Simplified Acute Physiology Score (SAPS II) based on a European/North American multicenter study. JAMA. 1993;270(24):2957-63.

14. Vincent JL, Moreno R, Takala J, Willatts S, De Mendonca A, Bruining H, Reinhart CK, Suter PM, Thijs LG. The SOFA (Sepsis-related Organ Failure Assessment) score to describe organ dysfunction/failure. On behalf of the Working Group on Sepsis-Related Problems of the European Society of Intensive Care Medicine. Intensive Care Med. 1996;22(7):707-10.

15. Wernovsky G, Wypij D, Jonas RA, Mayer Jr JE, Hanley FL, Hickey PR, Walsh AZ, Chang AC, Castaneda AR, Newburger JW, et al. Postoperative course and hemodynamic profile after the arterial switch operation in neonates and infants. A comparison of low-flow cardiopulmonary bypass and circulatory arrest. Circulation. 1995:92(8):2226-35.

16. The effects of tissue plasminogen activator, streptokinase, or both on coronary-artery patency, ventricular function, and survival after acute myocardial infarction. The GUSTO Angiographic Investigators. N Engl J Med. 1993: 329(22):1615-1622

17. Mehran R, Steg PG, White HD, Rao SV. Letter by Mehran et al regarding article, "Bleeding academic research consortium consensus report: the food and drug administration perspective". Circulation. 2012;125(10):e460.

18. Leplege A, Ecosse E, Verdier A, Perneger TV. The French SF-36 Health Survey: translation, cultural adaptation and preliminary psychometric evaluation. J Clin Epidemiol. 1998;51(11):1013-23.

19. Zigmond AS, Snaith RP. The hospital anxiety and depression scale. Acta Psychiatr Scand. 1983;67(6):361-70.

20. Horowitz M, Wilner N, Alvarez W. Impact of Event Scale: a measure of subjective stress. Psychosom Med. 1979;41(3):209-18.

21. Lawton MP, Brody EM. Assessment of older people: self-maintaining and instrumental activities of daily living. Gerontologist. 1969;9(3):179-86. 
22. Brechot N, Luyt CE, Schmidt M, Leprince P, Trouillet JL, Leger P, Pavie A, Chastre J, Combes A. Venoarterial extracorporeal membrane oxygenation support for refractory cardiovascular dysfunction during severe bacterial septic shock. Crit Care Med. 2013;41(7):1616-26.

23. Schmidt M, Zogheib E, Roze H, Repesse X, Lebreton G, Luyt CE, Trouillet JL, Brechot N, Nieszkowska A, Dupont H, et al. The PRESERVE mortality risk score and analysis of long-term outcomes after extracorporeal membrane oxygenation for severe acute respiratory distress syndrome. Intensive Care Med. 2013;39(10):1704-13.

24. Konstantinides S, Geibel A, Heusel G, Heinrich F, Kasper W, Management S. Prognosis of Pulmonary Embolism-3 Trial I. Heparin plus alteplase compared with heparin alone in patients with submassive pulmonary embolism. N Engl J Med. 2002;347(15):1143-50

25. Kasirajan V, Smedira NG, McCarthy JF, Casselman F, Boparai N, McCarthy PM. Risk factors for intracranial hemorrhage in adults on extracorporeal membrane oxygenation. Eur J Cardiothorac Surg. 1999;15(4):508-14.

26. Cengiz P, Seidel K, Rycus PT, Brogan TV, Roberts JS. Central nervous system complications during pediatric extracorporeal life support: incidence and risk factors. Crit Care Med. 2005;33(12):2817-24.

27. Schmidt M, Burrell A, Roberts L, Bailey M, Sheldrake J, Rycus PT, Hodgson C, Scheinkestel C, Cooper DJ, Thiagarajan RR, et al. Predicting survival after ECMO for refractory cardiogenic shock: the survival after veno-arterial-ECMO (SAVE)-score. Eur Heart J. 2015;36(33):2246-56.

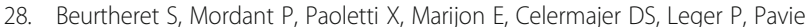
A, Combes A, Leprince P. Emergency circulatory support in refractory cardiogenic shock patients in remote institutions: a pilot study (the cardiacRESCUE program). Eur Heart J. 2013;34(2):112-20.

29. Wu MY, Liu YC, Tseng YH, Chang YS, Lin PJ, Wu TI. Pulmonary embolectomy in high-risk acute pulmonary embolism: the effectiveness of a comprehensive therapeutic algorithm including extracorporeal life support. Resuscitation. 2013;84(10):1365-70.

30. Munakata R, Yamamoto T, Hosokawa Y, Tokita Y, Akutsu K, Sato N, Murata S, Tajima H, Mizuno K, Tanaka K. Massive pulmonary embolism requiring extracorporeal life support treated with catheter-based interventions. Int Heart J. 2012;53(6):370-4.

31. Lang IM, Pesavento R, Bonderman D, Yuan JX. Risk factors and basic mechanisms of chronic thromboembolic pulmonary hypertension: a current understanding. Eur Respir J. 2013;41(2):462-8.

32. Delcroix M, Lang I, Pepke-Zaba J, Jansa P, D'Armini AM, Snijder R, Bresser P, Torbicki A, Mellemkjaer S, Lewczuk J, et al. Long-term outcome of patients with chronic thromboembolic pulmonary hypertension (CTEPH): results from an international prospective registry. Circulation. 2016;133(9):859-71.

33. Chen YS, Lin JW, Yu HY, Ko WJ, Jerng JS, Chang WT, Chen WJ, Huang SC, $\mathrm{Chi} \mathrm{NH}$, Wang $\mathrm{CH}$, et al. Cardiopulmonary resuscitation with assisted extracorporeal life-support versus conventional cardiopulmonary resuscitation in adults with in-hospital cardiac arrest: an observational study and propensity analysis. Lancet. 2008;372(9638):554-61.

34. Le Guen M, Nicolas-Robin A, Carreira S, Raux M, Leprince P, Riou B, Langeron $\mathrm{O}$. Extracorporeal life support following out-of-hospital refractory cardiac arrest. Crit Care. 2011:15(1):R29.

35. Kawahito K, Murata S, Adachi H, Ino T, Fuse K. Resuscitation and circulatory support using extracorporeal membrane oxygenation for fulminant pulmonary embolism. Artif Organs 2000;24(6):427-30.

36. Sakuma M, Nakamura M, Yamada N, Nakano T, Shirato K. Percutaneous cardiopulmonary support for the treatment of acute pulmonary embolism: summarized review of the literature in Japan including our own experience. Annals of vascular diseases 2009;2(1):7-16.

37. Omar HR, Miller J, Mangar D, Camporesi EM. Experience with extracorporeal membrane oxygenation in massive and submassive pulmonary embolism in a tertiary care center. Am J Emerg Med 2013;31(11):1616-17.

38. Maj G, Melisurgo G, De Bonis M, Pappalardo F: ECLS management in pulmonary embolism with cardiac arrest: which strategy is better? Resuscitation 2014;85(10):e175-76.

39. Swol J, Buchwald D, Strauch J, Schildhauer TA. Extracorporeal life support (ECLS) for cardiopulmonary resuscitation (CPR) with pulmonary embolism in surgical patients - a case series. Perfusion. 2016;31(1):54-59.

40. Cho YH, Sung K, Kim WS, Jeong DS. Management of acute massive pulmonary embolism: Is surgical embolectomy inferior to thrombolysis? International Journal of Cardiology 2016;203:579-83.

\section{Submit your next manuscript to BioMed Central and we will help you at every step:}

- We accept pre-submission inquiries

- Our selector tool helps you to find the most relevant journal

- We provide round the clock customer support

- Convenient online submission

- Thorough peer review

- Inclusion in PubMed and all major indexing services

- Maximum visibility for your research

Submit your manuscript at www.biomedcentral.com/submit

) Biomed Central 